\title{
Development of Open Geoinformation Resources in Russia
}

\author{
Elena Martynova \\ The Federal Service for State Registration, Cadastre and Cartography (Rosreestr), inter-dep@ rosreestr.ru
}

Keywords: Geospatial data, Geospatial technologies, Open data, NSDI

\begin{abstract}
:
Subject: T19. Open geospatial data and technologies

The strategic guide "Integrated Geospatial Information Framework", approved by the United Nations, defines the policy for the provision of geospatial data as one of the important factors for the successful development of geoinformation resources. The low availability of geospatial data not only leads to their insufficient use, but also hinders the emergence of innovative methods of applying data for various purposes.

Policies for open use of spatial data should be in line with the general national approach to the access to open data and technologies, as well as maintain a balance between the availability of information and the protection of private and public interests.
\end{abstract}

At the same time, the approach to the openness of spatial data and geoinformation technologies should take into account their high economic and social significance, as well as their potential for creating integrated information resources.

The concept of "Geospatial Knowledge Infrastructure" is being discussed internationally. It promotes integration of geospatial information into the digital data ecosystem and provision of integrated geospatial information, services and analytics, rather than separate data.

Aspiring to the effective use of spatial data, Rosreestr is working on the creation of new information resources that deliver open access to reliable data and interoperability with other systems.

In Russia, the creation of a unified system for identification of spatial objects was launched by the Government Decree No. 1157-r, which approved the Concept of Creating and Developing the Spatial Data Infrastructure of the Russian Federation (SDI of the Russian Federation).

The formation of the SDI of the Russian Federation ensures the effective use of spatial data, the creation of spatial data banks as state information resources.

The main challenge for formation of the SDI at present is insufficiency of a unified system for identifying spatial objects in the Russian Federation, which prevents the use of spatial data created by different organizations as a universal element of communication between different databases.

The most urgent task is to ensure the transition to the use of standardized spatial data, which allows creation of a system for managing related data and subsequent integration of national data into the global system.

Currently Rosreestr is implementing an experiment on creation of a single digital resource that combines all possible spatial data in the Russian Federation for the purposes of public administration based on geospatial analytics.

The resource will ensure consolidation and relevance of all available geodata in Russia online on a single digital platform. 